\title{
Pesquisa da Prevalência do Papilomavirus Humano (HPV) em Amostras de Tecido Endometrial Normal e com Carcinoma pela Técnica de PCR
}

Study on the Prevalence of Human Papillomavirus (HPV) in Samples of Endometrial Tissue, both Normal and with Carcinoma, using the PCR Technique

Edison Natal Fedrizzi, Newton Sérgio de Carvalho, Luisa Lina Villa, Irene Vieira de Souza, Ana Paula Martins Sebastião

Objetivo: comparar a prevalência da presença do DNA do HPV pela técnica de PCR em amostras de tecido endometrial normal e com carcinoma endometrial de mulheres submetidas a tratamento cirúrgico (histerectomia) por carcinoma endometrial e doença benigna e a sua correlação com a idade, tabagismo, diferenciação escamosa e grau de diferenciação tumoral, tipo viral mais frequente e trofismo endometrial nas mulheres sem carcinoma.

Métodos: trata-se de estudo observacional do tipo caso-controle em que foram avaliadas 100 mulheres (50 com endométrio normal e $50 \mathrm{com}$ carcinoma endometrial) quanto à presença do DNA do HPV em amostra tecidual conservada em blocos de parafina, pelo método de PCR.

Resultados: o risco relativo estimado da presença do HPV foi o mesmo nas mulheres com e sem carcinoma endometrial. A presença do HPV não esteve correlacionada com a idade das mulheres, tabagismo, trofismo endometrial, diferenciação escamosa e grau de diferenciação tumoral. O HPV 16 e 18 (5 dos casos com tipo 16 e 4 com o tipo 18) foram os virus mais freqüentemente encontrados.

Conclusão: o HPV está presente no tecido endometrial de mulheres com carcinoma endometrial na mesma proporção que nas com tecido endometrial normal, não demonstrando a possivel associação deste vírus no desenvolvimento do carcinoma endometrial.

PALAVRAS-CHAVE: Papilomavirus humano. HPV. Oncogênese. Carcinoma endometrial. 